\title{
Intimate Partner Violence and COVID-19 in Rural, Remote, and Northern Canada: Relationship, Vulnerability and Risk
}

\author{
Pertice Moffitt ${ }^{1}$ - Wendy Aujla ${ }^{2} \cdot$ Crystal J. Giesbrecht ${ }^{3} \cdot$ Isabel Grant $^{4} \cdot$ Anna-Lee Straatman $^{5}$
}

Accepted: 4 October 2020 / Published online: 19 November 2020

(C) Springer Science+Business Media, LLC, part of Springer Nature 2020

\begin{abstract}
In rural, remote, and northern parts of Canada, the pre-existing vulnerability and risk for intimate partner violence has been exacerbated by COVID-19. The purpose of this commentary is to identify the unique impact of COVID-19 on intimate partner violence both in terms of the bearing on those experiencing abuse and on the service sector in rural, remote and northern communities where the rates of intimate partner violence and intimate partner femicide pre-pandemic are higher than in larger cities. The recommendations offered in this paper include enhanced safety planning, alternate housing for victims fleeing violence, and suggestions for service providers. We also offer ways to move forward with further research in the COVID-19 era.
\end{abstract}

Keywords Coronavirus $\cdot$ COVID-19 pandemic $\cdot$ Intimate partner violence $\cdot$ Domestic violence $\cdot$ Rural $\cdot$ Remote $\cdot$ And northern $\cdot$ Canada

On March 18, a public health state of emergency was declared in the Northwest Territories (Government of NWT 2020) joining many other provinces and territories in Canada. According to the Chief Public Health Officer (CPHO), this action was required to protect citizens during the pandemic. By establishing a State of Emergency, ${ }^{1}$ the $\mathrm{CPHO}$ is granted powers to purchase additional medical supplies; make orders that restrict movement in and out of the territory; sanction containment efforts requiring people to self-isolate and practice physical distancing; plan, coordinate, and implement health care system personnel; and, expedite jurisdictional licensing if additional staff are required (Government of NWT 2020).

\footnotetext{
${ }^{1}$ In RRN Canada, isolation is often experienced but now it is sanctioned by government to a greater extreme: the borders are closed with limited travel in or out by only essential services; travellers returning to their homes are mandated to self-isolate for fourteen days; gatherings are restricted to only immediate family within a household. Physical distancing disrupts relationships and displaces families from their frequent visits with brothers, sisters, grandparents, etc.; many items are restricted for purchase by families, such as, toilet paper, a valued commodity, as people fearfully prepare for the unknown; staples like yeast for making bread are in low supply; citizens are encouraged to stock their cupboards; the stress and fear of acquiring COVID-19 is leading to increased calls on the help-lines.
}

\section{Pertice Moffitt}

pmoffitt@auroracollege.nt.ca

Wendy Aujla

waujla@ualberta.ca

Crystal J. Giesbrecht

paths.research@sasktel.net

Isabel Grant

grant@allard.ubc.ca
Anna-Lee Straatman

astraat2@uwo.ca

1 Health Research Programs, Aurora Research Institute/Aurora College, Yellowknife, NT, Canada

2 University of Alberta, Edmonton, AB, Canada

3 Provincial Association of Transition Houses and Services of Saskatchewan (PATHS), Regina, SK, Canada

4 University of British Columbia, Vancouver, Canada

5 University of Western Ontario, London, Ontario, Canada 
Others have suggested that with the onset of the COVID-19 global pandemic, an increase in intimate partner violence (IPV, also known as domestic violence) is to be expected (Peterman et al. 2020). Vulnerability and risk are central to this hypothesis. The factors that create vulnerability and risk in pandemics are concomitant to IPV (Peterman et al. 2020), particularly in rural, remote, and northern (RRN) areas. ${ }^{2}$ The IPV sector is reacting to this global health crisis and the challenges with physical distancing and other public health measures in all of the provinces and territories (Government of Canada 2020). The restrictions imposed on the public, and stay at home measures to prevent the coronavirus from spreading across communities, will inevitably have an effect on IPV behind closed doors.

The United Nations sexual and reproductive health agency has estimated that, worldwide, 15 million cases of gender-based violence will occur for every three additional months of the lockdown (UNFPA 2020). Other impacts of the pandemic are felt disproportionately by women, as well, such as a lack of access to family planning (UNFPA 2020). Spikes in incidents of IPV have been reported in countries where the impact of COVID-19 was first seen, including China and France (Godin 2020; Le Page 2020). While it is not yet possible to measure the impact of COVID-19 on rates of IPV incidents here in Canada, a recent Statistics Canada (2020) survey found that "one in 10 women is very or extremely concerned about the possibility of violence in the home." Further, a survey of more than 250 Indigenous women conducted by the Native Women's Association of Canada found that one in five had experienced physical or psychological violence during the last three months of the pandemic (NWAC 2020; Wright 2020).

On April 16, 2020, The United Nations Secretary-General Antonio Guterres urged all governments to prioritize the safety of women during the pandemic (United Nations 2020). Soon after, on April 18-19, Canada experienced a mass murder in rural Nova Scotia that began with the perpetrator assaulting his intimate partner (Thomson and Chiu 2020). From this initial assault of his partner, the perpetrator went on to murder 22 people. Although these homicides have not been linked to COVID-19, the fact that they occurred in rural Nova Scotia in the midst of social distancing and

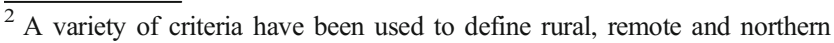
$(\mathrm{RRN})$ regions when examining IPV in Canada. Sometimes a location may be used such as naming northern jurisdictions, like the Northwest Territories, or rural or remote regions of provinces (Moffitt et al. 2013; Wuerch et al. 2019). This paper is based on three distinctly different geographical contexts in Canada- rural, remote and northern (RRN). These areas share commonalities, particularly when describing vulnerabilities and risk, which we will highlight in the paper.
}

corresponding increased isolation, suggests that the vulnerability of the victims may have been enhanced by COVID- 19 .

The purpose of this commentary ${ }^{3}$ is to identify the challenges related to the evolving occurrence of COVID-19 for those facing IPV in RRN communities. We call for further action to respond to identified gaps in the supports for those impacted by IPV during the pandemic, including appropriate prevention and intervention strategies to improve the response to IPV during the current crisis and potential future waves of the pandemic.

Nearly $80 \%$ (79\%) of police-reported victims of IPV in Canada are female (Burczycka 2019). On average, 69 women are killed by intimate partners in Canada every year (Roy and Marcellus 2019). In addition, women experience the most serious and life-threatening forms of IPV (Sinha 2013). For these reasons, we focus this commentary on IPV perpetrated by men against female partners in the context of cohabitating couples. This violence is often accompanied by coercive controlling behaviours, which Evan Stark describes as a pattern of behaviour men use "to hurt, humiliate, intimidate, exploit, isolate, and dominate their victims" (Stark 2007, p. 5). Coercive controlling behaviours that isolate women from their support networks are particularly dangerous for women in the context of the mandated social isolation that has accompanied COVID-19 (see Slakoff et al. 2020 for examples).

In this commentary, we begin by defining RRN communities, followed by the historical accounts of epidemics, and then the multiple intersecting risk factors and barriers to reporting IPV. We describe how seeking help and access to services is often extremely difficult for women in RRN communities. Then we offer practical recommendations to address risk assessment, risk management, and safety planning. Finally, we call for additional research, as more information is needed to support women in RRN communities.

\section{Rural, Remote, and Northern (RRN) Communities and Intimate Partner Violence (IPV) Statistics}

Canada is a vast country with the majority of its population concentrated in large urban cities along or close to its southern border. Approximately $19 \%$ of Canadians live in rural areas (macrotrends.net). While there is a lack of consensus on how to define rural, in this paper, we use the working definitions that are provided by the Canadian Domestic Homicide Prevention Initiative with Vulnerable Populations (CDHPIVP):

\footnotetext{
${ }^{3}$ Please note we are concerned about the community response to IPV and fear that women are in most danger when they are unable to reach out to informal/ formal supports. While anecdotal evidence suggests that cases are spiking due to coronavirus-related quarantines we are not able to comment on this without research that examines whether incidents are increasing. We recognize that this data might not be available until much later.
} 
- Rural: A community or geographic location with a population less than 10,000 (Bollman 2016; Statistics Canada 2020)

- Remote: A community or geographic location that is not accessible by road year-round (Ontario Ministry of Health and Long-Term Care 2011).

- Northern: A community or geographic location that is designated by the provincial government as being the northern part of the province (e.g., for British Columbia, see Northern Development Initiative Trust, 2018; for Ontario, see Northern Ontario Heritage Fund Corporation 2018). All the Canadian territories are considered northern (Jeffrey et al. 2019).

RRN communities often have small populations of 5000 or less and with tight-knit communities where relationships among residents are strong (Jeffrey et al. 2019). The makeup of these communities varies with some being scattered farming families in rural areas or fly-in communities in the north that have no road access and can only be reached by air. Indigenous women represent a large portion of the RRN population in Canada, particularly in the north, but only $4 \%$ of the total female population of Canada. In the three northern territories of Canada, Indigenous women represent $25 \%$ of the female population in the Yukon, $54 \%$ in the Northwest territories and $87 \%$ in Nunavut. One fifth of Indigenous women (First Nations, Inuit and Métis) live in rural areas in Canada. Just over one third of First Nations women live on reserves (Arriagada 2016). Slightly less than one quarter of First Nations women living off-reserve live in rural areas, and more than one quarter of Métis women in Canada live in rural areas (Arriagada 2016). While focusing on rural communities contributes to an intersectional analysis of IPV, we recognize the danger of contributing to marginalization of rurality by reinforcing images and perceptions of rural locations and rural inhabitants as aberrant which contributes to further vulnerability (Sandberg 2013).

It is important to examine and understand the context of IPV and domestic homicides in these communities. The Canadian Femicide Observatory for Justice and Accountability reported that $38 \%$ of women and girls killed in 2019 lived in RRN regions or small towns (CFOJA 2020). Although less than $20 \%$ of the population of Canada lives in these regions, more than one quarter $(28 \%)$ of the domestic homicides (which sometimes include other victims connected to the female intimate partner) in Canada from 2010 to 2018 involved RRN populations (CDHPIVP 2019). Over this eight-year period, victims of domestic homicide were primarily women $(78 \%)$, nearly one quarter were identified as Indigenous (23\%), and $14 \%$ were children. Half of the homicides involved a victim and accused in a common-law or legal marriage relationship. There was a known history of IPV in $29 \%$ of the cases, and more than one-third of the cases involved firearms (36\%) (CDHPIVP 2019). Between 2002 and 2017, more than one-quarter of domestic homicides in Ontario were committed with firearms (DVDRC, 2018). Perpetrators of domestic homicide in rural areas in Ontario were more likely to have access to a firearm than in urban Onatrio and to use it to kill their partner (Banman 2015).

Just as statistics have helped to identify the impact of pandemics, Elders, as traditional knowledge keepers, have preserved and communicated stories of past pandemics and the devastating effects on the lives of their ancestors. The current isolation under COVID-19 by RRN Indigenous communities has been experienced before with separation of families and high death tolls, leaving a lasting fear about what may occur. Recent studies based on crowd-sourced data conducted by Statistics Canada suggest that Indigenous women are more likely to report concern about the impact of confinement on family stress and twice as likely to report concern over violence in the home compared to non-Indigenous women during COVID-19 (Arriagada et al. 2020).

\section{Stories about Epidemics and Indigenous Storytellers}

Since early contact between Europeans and Indigenous peoples in Canada, there have been records of disease outbreaks, such as smallpox, scarlet fever, tuberculosis, and influenza (Abel 1993; Blondin 1990; Helm 2000; Truth and Reconciliation Commission 2015). In the North, Indigenous people have accounts of historic and more recent outbreaks and epidemics in oral history (Blondin 1990). George Blondin, a Dene Elder, explains it this way:

By 1910, the people's health had started to change. New kinds of diseases affected them. There were many sicknesses they had never seen before and couldn't deal with, but things didn't get really bad until the great epidemic of 1928. The influenza spread in July, through all the settlements along Dehcho. It appears to be brought by infected passengers aboard the Hudson's Bay Company Steamer, S.S. Distributor (p. 171).

While some details of these historic outbreaks can be found in archives, the records and numbers have been difficult to ascertain in the historical record given the very limited written records available. Oral history of local Indigenous peoples provides more detail on the actual experience and impacts this had on their culture and communities, whereas records mostly kept by missionaries or mentioned in fur trade log books - provide a look from those who were able to visit trading posts and missions, as well as the impact that disease had on the children being held in residential schools (Truth and Reconciliation Commission 2015). Communicable disease should thus be understood as an additional component of colonization, with its corresponding loss of Elders and of 
traditional knowledge, which in turn caused extreme devastation and cultural suffering (Moffitt 2004). Historically, these outbreaks arrived initially with travellers from southern Canada. Recently, Northern communities have expressed concern about travellers from the south coming to their communities to try to avoid COVID-19.

Stories about epidemics and outbreaks have been recounted by Elders sharing experiences about health. For example, while conducting breastfeeding research and speaking with grandmothers, a researcher was told about how the 1928 flu epidemic wiped out families up and down the Dehcho (Mackenzie) River. In particular, a Kátt'odeeche Grandmother recalled her father describing how he lost his mother through the flu epidemic when he was an infant (Moffitt and Fikowski 2017). The grandmother described the "pitiful" situation as older children raised younger children and, rather than breastmilk, caribou and fish broth were used to nourish infants who had lost their mothers. These stories reveal the extent to which the impacts of epidemics are personal, situational and contextual in the degree to which resilience and persistence are necessary to survive hardships (P. Moffitt, personal communication, November 29, 2017).

In addition, as this pandemic continues, Elders are sharing stories of violence as a response to past and current epidemics and in terms of the intergenerational trauma epidemics and outbreaks produced. One Elder told her perspective in this way:

Violence is due to many things... but in the past first Europeans brought disease to the people. People did not get proper treatment and did not know how to treat each other... ... People died everyday, and the relatives had to bury them together, and this upset the survivors. It made them angry, and they took it out on each other... People got very emotional because of all the killings they had in their lifetime, so brutal. It created more anger that turned into violence, and today we can still sense the hate. Three days ago, I had to call the nurse for an elderly woman attacked by her husband. He forcibly spilled hot soup on her...I called the nurse at the clinic... Later, I saw the burn. It was red and blistered, so painful...The community is working towards prevention. It is not helping the whole community. Many people are not practicing our traditional way of life, so not helping, and it is downsizing our strength to weakness (Tlicho Elder, personal communication, September 8, 2020).

Indigenous scholars suggest that sharing traditional practices are an important response to COVID-19-for example, Indigenous communities combat isolation by accessing virtual traditional dancing, drumming, and dancing lessons. Traditional food systems, community gardens, and excursions on the land are providing continuity and renewal (National Collaborating Centre for Determinants of Health 2020). In Northern Canada, one Indigenous group is engaged in a language revitalization project virtually through zoom where Gwich'in Elders are teaching young people their language though talks twice weekly. Indigenous people are finding new and safe ways to create community and share knowledge. In this time of COVID-19, Elders in the north posit that "information is medicine" (Hoti Ts'eeda, personal communication, April 30, 2020). They remember past encounters with epidemics, how these health disturbances exacerbated violence, and by sharing their learnings and experiences, a deeper understanding helps community people respond to the current pandemic. Local community radio is active with information sharing as public health bulletins arrive in communities and local health representatives translate key messages to local language.

\section{Multiple Intersecting Risk Factors and Barriers to Reporting Intimate Partner Violence}

During this novel time, media reports around the world describe how the pandemic may be fueling IPV at an alarming rate. $\mathrm{ABC}$ News reporters from Melbourne, Australia, report psychological manipulation by abusers holding victims hostage with the threat of the virus to keep them at home (Gearin and Knight 2020). Communities in RRN areas experience increased risk of IPV, and the COVID-19 pandemic contributes to additional challenges when the public is asked to stay home. These challenges have created what has been described by some authors as a perfect storm for both IPV and COVID19 (Usher et al. 2020). In the following section, we outline the multiple intersecting risk factors for IPV. These risk factors can be conceptualized into two overlapping categories when reflecting on the reality of IPV in RRN communities: first, personal/cultural dynamics and second, structural/ institutional barriers.

\section{Personal/Cultural Dynamics}

\section{Understanding Community Pressures}

In small and remote, often tight-knit communities, reporting abuse and accessing services raises challenging issues around anonymity and confidentiality (Moffitt and Fikowski 2017; Wuerch et al. 2019). Most inhabitants of small communities have quite extensive knowledge of the lives of others in their community. In the case of IPV, this knowledge can amplify hurtful community gossip, generate retribution by one family against another or within families, increase the marginalization and stigma faced by victims of IPV, and may serve to silence victims of violence as a form of self-protection (Faller 
et al. 2018; Moffitt and Fikowski 2017). The stigmatization of victims of communicable disease, including frontline workers, was seen during the Ebola outbreak in Africa (Van Bortel et al. 2016) and SARS in Canada (Cava et al. 2005). In the U.S. and Canada, for example, we have seen victim-blaming and racism against Asians (Liao 2020) in light of the COVID19 pandemic, which is problematic. Jurisdictional Chief Public Health Officers have decreed that they will not identify cases of COVID-19 in small communities (CBC News 2020 b) because of the potential for victim-blaming and racial discrimination. There is resistance from some community leaders who argue that community safety takes precedence over personal safety (CBC News 2020b). Given the lack of privacy and anonymity in remote places, the risks involved in identifying individuals with COVID-19 are significant.

It is important to recognize the intersections and complexity of RRN women's choices in deciding whether to report IPV and whether to stay or leave a relationship (Goodkind et al. 2004). The realities of life in rural communities may constrain women's choices in dealing with violent relationships. Challenges in transportation, communication, emergency housing and access to other resources may create additional barriers for women in RRN communities (Bosch and Bergen 2006; Northcott 2011). Women in these communities may choose to stay with abusive partners for personal, social, economic (e.g. possibility of losing one's children or assets) and cultural reasons (e.g. fear of losing face [self-dignity and preservation] because of complex relationships among the victim, abuser, and other family or community members). The informal and formal supports that could help women in RRN communities to deal with the abuse are often different, not as helpful and less readily available, from those in large urban areas (Bosch and Bergen 2006). Sometimes women choose not to access services from IPV professionals and feel safest by using a variety of strategies that they believe may be effective for them in the short-term such as enduring the abuse or visiting family, friends or neighbours (Bosch and Bergen 2006; Lindhorst et al. 2005). During the present time of pandemic-related precautions, such as physical distancing, even these options or opportunities become severely limited.

\section{Considering Cultural Realities}

Multiple intersecting factors create an environment conducive to IPV, including social inequities and oppression, colonization and power imbalances, poverty, inadequate housing and minimal educational opportunities, along with gender and racial biases (Royal Commission on Aboriginal Peoples 1996: Truth and Reconciliation Commission 2015). Recently, in Canada, intimate partner violence as been described as a social determinant of health for Indigenous peoples (National Collaborating Centre for Indigenous Health 2019). Indigenous scholars have demonstrated how COVID-19 intensifies the inequities and social determinants that fuel IPV (e.g., lockdowns, economic hardships, food insecurity, social isolation, access to housing and clean water, and more) and compromised afety when guidelines for COVID-19 are not translated to local language (National Collaborating Centre 2020). Food insecurity is already present in many RRN communities, and COVID-19 may well aggravate food shortages.

Intergenerational trauma is an outcome of historic and ongoing colonialism in Indigenous communities. In the NWT, many Indigenous communities emphasize the importance of reconnecting to their culture and identity by going on the land. ${ }^{4}$ In today's bureaucratized society, this has resulted in an emphasis on receiving funding and support for on-the-land programs. Indigenous people hold a special relationship with the land, and many traditional activities and gatherings are a part of their lifeways. Physical distancing is a global intervention to prevent the spread of the pandemic and flatten the curve. We know that physical distancing is difficult for all people and dangerous for victims, but this intervention creates particularly difficult challenges for those whose culture and identity are expressed through gatherings to drum, dance, celebrate, and restore spiritual selves after decades of colonial harassment. Physical distancing requirements may be perceived as one more form of colonial control, limiting access to Indigenous culture.

\section{Alcohol Consumption as a Risk Factor}

Early data suggests that some Canadians may be increasing their alcohol consumption while staying home during COVID-19 (Canadian Centre on Substance Abuse and Addiction 2020). A survey of alcohol consumption during the COVID-19 pandemic indicates that women cited stress as a reason for increased consumption, whereas men cited boredom (Canadian Centre on Substance Abuse and Addiction 2020). A poll conducted by the Canadian Centre on Substance Abuse and Addiction (2020) in March-April 2020 found that $25 \%$ of Canadians ages $35-54$ and $21 \%$ of Canadians 18-34 reported increased alcohol consumption while spending more time at home during the COVID-19 pandemic. Some survivors use alcohol or other substances as a way to cope with the abuse that they are experiencing. Such strategies may be accompanied by addictions and mental health concerns, which in turn can lead to shame and further reduce interaction with IPV professionals.

According to the World Health Organization (WHO), alcohol consumption increases the risk for IPV and COVID-19

\footnotetext{
${ }^{4}$ The relationship of the land to Indigenous people is unique. It is most often described as a way of life with cultural knowledge, celebration, community and rituals embedded in Indigenous cultures. This stems from a holistic perspective of the world and a relationship to all living beings that grow and live on the land.
} 
(WHO n.d.). Similarly, van Gelder et al. (2020) note that forced isolation and economic stressors during the pandemic may lead individuals to turn to unhealthy coping mechanisms (e.g., alcohol consumption), which can increase the risk of IPV. Excessive use of alcohol was identified as a risk factor for intimate partner homicide in $40 \%$ of cases reviewed in Ontario between 2003 and 2018 (Office of the Chief Coroner 2019). Alcohol consumption, particularly at high levels, is a contributor to IPV, mainly because alcohol affects cognitive and physical function, reducing self-control (WHO n.d.). The alcohol does not cause the violence to occur but may cause situations to become more volatile, increasing the frequency and severity of abuse.

Disagreements have arisen about the appropriate response to managing and restricting alcohol during the pandemic. Prince Edward Island announced that it would close all liquor stores in the province on March 19, 2020. Newfoundland and Labrador closed stores but allowed telephone and online orders (CBC News 2020a). Other jurisdictions have deemed alcohol sales an essential service. As well, managed alcohol programs are in place and remain open in two regional centres in the north (Inuvik and Yellowknife). Since early April, some Indigenous leaders have advocated for restrictions on alcohol. Generally, local leadership in the NWT has been described as split over whether to restrict alcohol during the pandemic (Brockman 2020). Leaders supporting restrictions stated that limiting the availability of alcohol would lessen parties/social gatherings and keep communities healthier. Other leaders expressed concerns that restrictions would negatively affect a large number of heavy drinkers/addicts, inducing withdrawal with poor outcomes (stroke, seizures) due to a lack of services. Some who support restrictions point to the fact that alcohol dependency is related to coping with trauma from colonial processes and residential schools. Whether one argues for or against community restrictions to alcohol, alcohol consumption remains a risk for both IPV and COVID-19 because this practice negatively influences safe decisionmaking.

\section{Structural/Institutional Barriers}

\section{Geographic Barriers by Distance}

Geographic distance is a barrier to safety for victims experiencing IPV in RRN Canada. For survivors in rural and isolated areas, police response time is a barrier to reporting - and to receiving assistance in times of danger. Police response to calls has also been affected due to COVID-19. Dispatchers have been asking additional questions related to COVID-19 before responding to calls (Roszell 2020). In some cases, the police may not respond to the call-in person, but only over the phone. Isolation, in terms of distance to services and distance for police to travel to respond, may act as deterrents to victims when deciding whether to seek assistance (Faller et al. 2018).

Distance is also a barrier to accessing IPV shelters or other services. For RRN women, these services are often situated hours away from their home. Leaving home to go to a shelter requires an enormous amount of planning, especially for women who live-in fly-in communities, those who live in communities without year-round access by road, and those in areas of the country without inter-city bus services. These transportation challenges are significantly exacerbated by Canada's weather. In many parts of Canada, especially the rural and remote north, winter conditions make it unsafe - or impossible - to travel at certain times. Significant travel is required to reach services located in larger urban centres. Sometimes, women must resort to creative transportation such as boats and snowmobiles or choose potentially dangerous methods, such as hitchhiking; should they decide to leave due to a personal safety crisis, options may be limited. Further, the subsequent return to home and community may be obstructed due to isolation and quarantine restrictions put in place during the pandemic.

The choice to leave home is even more difficult for women in rural and remote areas or who live on First Nations reserves. ${ }^{5}$ For many of these women, leaving means moving away from their communities, culture, relatives, those who speak their language (especially for northern Indigenous women), and leaving their chosen rural lifestyle. For many women in RRN communities, relocating to an urban centre for safety from violence is not an easy choice.

Women who own pets or livestock face additional barriers to leaving. Research has shown that many survivors have especially strong bonds with their pets (Barrett et al. 2018), and pets are an important source of comfort and emotional support. Being separated from companion animals adds to the trauma of leaving. Further, harm may be inflicted on animals if they are left with the perpetrator (Barrett et al. 2020). Given transportation barriers, it can be difficult to take pets when escaping and finding safekeeping or fostering options for pets can prove challenging in small communities. Further, for women who work on farms and own livestock, leaving an abusive relationship means giving up their livelihood, and leaving animals behind - potentially risking the animals' well being (Wuerch et al. 2018; Wuerch et al. 2017). For these reasons, women who own animals may delay leaving or stay in a home where IPV is taking place.

\footnotetext{
${ }^{5}$ Reserves for First Nations are found mostly in southern Canada. In the Canadian north, many Indigenous people do not live on reserves. The proportion of Indigenous people to other Canadians in the North is much higher and in both the Northwest Territories and Nunavut, the majority of the population are Indigenous/First Nations.
} 


\section{Access to Shelters and Transitional Housing}

Access to shelters and transition houses may become more challenging during times of physical distancing, particularly in RRN areas. Advocates are trying to communicate information about access to shelters; however, it appears that many people are still confused about whether shelters are open, creating disparity and danger for local women, as reported by one Director who declared that for the first time in 23 years, in the month of April, 2020, no women and children who were fleeing violence accessed the shelter (CBC News 2020d). There was concern expressed that perhaps women felt that physical distancing would not be possible in the shelter, which prompted better messaging about the changes that had been made to keep women safe from perpetrators and COVID-19.

There are 552 domestic violence shelters ( 428 shorter-term shelters and $124 \mathrm{~s} \mathrm{stage}^{6}$ ) in Canada, with 30 located on reserves (Moreau 2019). Just over one-third of shelters serve small populations and rural areas (Maki 2018). Four percent of the shelters served population areas of less than 1000 people (Beattie and Hutchins 2015; Maki 2018), and ten shelters were located in fly-in communities (Maki 2018). Less than half of shelters and transition homes in small and rural communities report access to public transportation in their community. Most rural shelters and transition homes reported a lower rate of access to mental health services and victim support for children than urban and suburban shelters (Maki 2018). Access to shelters in northern Canada is also more limited. In 2017, in the NWT, for example, only five of 33 communities had emergency shelters for women fleeing violence (Moffitt and Fikowski 2017).

Since the start of the coronavirus pandemic, some domestic violence shelters and crisis lines have reported significant increases in calls (Bogart 2020), whereas others are receiving fewer calls (Michelin 2020), causing advocates to worry that those who are in danger may not know that shelters are open or may be unable to call, due to isolation with their abusive partner. The fear of the virus, the stay-at-home messaging, and uncertainty about whether shelters are open and safe may be keeping women away. These concerns isolate women who are endangered in potentially unsafe homes. Advocates are doing their best to communicate to the public that shelters and crisis lines remain open during the pandemic and that shelters are taking added precautions for the health and safety of clients and staff. Outreach and support services can be provided via telephone or videoconferencing, in accordance with guidelines for health and safety, assuming a woman has safe access to these. While messaging is being communicated via shelters' websites, media interviews, and via social media, confusion and misinformation may remain additional challenges.

\footnotetext{
${ }^{6}$ For more information on the shelters available in Canada and types of services offered see Aujla (2010).
}

Prior to the COVID-19 pandemic, the majority of domestic violence shelters reported that their clients struggled to find affordable housing in their community when leaving the shelter (Maki 2019). In RRN communities, access to safe and affordable housing is even more limited (Maki 2018) and will continue to be post-pandemic. Recently, in some communities, IPV shelters have been able to work with their local social housing authorities to allow survivors to move directly into social housing through an expedited process (Provincial Association of Transition Houses and Services of Saskatchewan (PATHS), personal communication, May 6, 2020).

\section{Access to Adequate Telephone and Internet Services}

Along with the housing inadequacies, shortages and overcrowding, there are women without access to reliable telephone and internet service, which enhances their social isolation and hinders their ability to get help when needed (Bosch and Bergen 2006). Canadians living in rural communities have fewer internet service providers to choose from, lower service speeds, and lower monthly data transfer limits than those living in urban communities. Only $40 \%$ of rural households have access to $50 \mathrm{Mbps}$ download service speeds compared to $97 \%$ of those in urban areas (CRTC 2019). In addition to poorer quality service, people living in the north pay as much as three times more for these services, when available, as those living in the south. Limited availability of or access to high-speed internet creates challenges for those who must now rely on internet-based communications and support services. In some parts of Canada, survivors of violence can be provided with free cell phones (for example: SaskTel 2020). Yukon territory also made cell phones available to women specifically due to risk of IPV during the time of COVID19. Social support service providers may also be limited in the support they can provide in RRN settings if forced to rely solely on the internet and wireless communication.

\section{Service Delivery Challenges}

Providing services to victims of IPV in RRN communities is always challenging, and a global pandemic now heightens these challenges. IPV service providers may experience frustration and feel that their hands are tied when trying to support women dealing with myriad issues including poverty, unemployment, lack of resources, isolation, Indigenous concerns, and challenges with the legal system (Faller et al. 2018; Wuerch et al. 2019). Other staffing issues, including high turnover rates, inadequate training, staff shortages and burnout, also contribute to challenges in service provision (Faller et al. 2018; Moffitt and Fikowski 2017; Wendt et al. 2017; Wuerch et al. 2019). 


\section{Financial Aid and Supports}

In April 2020, the Government of Canada, under the leadership of Prime Minister Trudeau, announced additional funding of up to $\$ 40$ million to support services for survivors of violence across Canada, including up to $\$ 4$ million for sexual assault centres, up to $\$ 10$ million for 46 emergency shelters for Indigenous women and their children, and up to $\$ 26$ million to be distributed among Canada's domestic violence shelters. Women and Gender Equality Canada (WAGE) partnered with Women's Shelters Canada (WSC) (the national association for domestic violence shelters) to distribute the \$26 million allocated to domestic violence shelters. WSC worked in partnership with its membership of domestic violence shelters across Canada and provincial and territorial shelter associations to develop a process for distributing the funds. The first round of funding was delivered in April 2020, and shelters have the opportunity to apply to WSC for additional funds if they face a greater need (WAGE 2020; WSC 2020).

This funding was welcomed by IPV services that were braced to experience budgetary constraints due to COVID19. Some agencies have had to cancel planned fundraising activities, and rescheduling remains a challenge, as they await directions from public health officials. Further, the pandemic will inevitably have an economic impact on non-profit organizations that depend on donations to meet their annual targets (Smith 2020). Additional funding challenges for IPV services include paying casual staff to fill in for staff members who become ill, additional personal protective equipment (PPE) for staff and clients, and extra cleaning supplies.

The layout of many of Canada's IPV shelters (where each family has their private bedroom but share the kitchen, washroom, and communal areas with other families), means that agencies will be able to accommodate fewer families at a time to comply with physical distancing guidelines. In some cases, this requires paying for hotel rooms to house families who cannot be accommodated in shelters. Some clients are being housed in hotel rooms to self-isolate, such as where they or their partner may have been exposed to the virus (Bogart 2020). All of these unique circumstances place additional strain on shelters, the majority of which were already operating with insufficient funding (Maki 2018).

\section{Recommendations Moving Forward}

Under the current state of a public health emergency, the IPV sector and funders will need to think of a response to help individuals in RRN areas to heal from abuse during and after COVID-19. This response should consider unique ways to keep victims of violence safe while managing social isolation and physical distancing. Additionally, support systems cannot ignore the ongoing trauma and shame survivors in these isolated areas experience. We propose some practical recommendations that address risk assessment, risk management, and safety planning.

\section{Risk Assessment, Risk Management, and Safety Planning}

As the message to stay home and physically distance is widely shared, the risk of IPV increases. Despite the fact that shelters remain open and crisis lines and outreach services remain accessible, the messaging around staying home and socially distancing may be interpreted by some women as meaning they should stay at home with their abuser. For other women, fears around contracting the virus may lead them to avoid reaching out for help during this time. Some survivors may be choosing to wait this time out, staying home for as long as they can. When women do seek help, police responses may be more limited during COVID-19. In the context of the pandemic, women who choose to leave face heightened barriers. Given physical distancing and many people unemployed or working remotely, women do not have time away from their partners to talk to IPV professionals, search for information, or make plans. For women who have lost work outside of the home due to the pandemic, a crucial source of safety, information, and connection with other people and resources has been lost. Other women have found their partners suddenly unemployed and at home all the time, which may increase the risk of coercively controlling behaviours (see Slakoff et al. 2020; Stark 2007) and regulation of women's activities. As is always the case, the most dangerous time for many victims is when they choose to leave, or their partner believes that they are planning to leave (Office of the Chief Coroner for Ontario 2019).

Risk management involves working with perpetrators to identify strategies to reduce the risk of intimate partner violence. This may include activities such as close monitoring or supervision and psychosocial interventions to address the violence and/or related issues such as mental health and addictions (Campbell et al. 2016). Risk management with perpetrators will need increased attention. Some abusers may face unemployment, and the ensuing financial struggles or frustration regarding shared parenting time or lack of supervised visitation with children. Batterer intervention programs have had to adapt and find ways to offer support and services. Some perpetrators have been released from detention due to concerns about COVID-19 in correctional institutions (The Star 2020). Those who supervise and support abusers may be restricted in the risk management options they can utilize due to the suspension of domestic violence courts (CBC News 2020c) in-person meetings, substance abuse, anger management, and other treatment and monitoring options.

Risk assessment involves evaluating the level of risk of harm a victim may be facing, including the likelihood of repeated or lethal violence based on a professional's judgment and/or use of a structured interview or tool that may include a 
checklist of risk factors (Campbell et al. 2016). Safety planning involves identifying specific strategies that women experiencing IPV and their children can use to protect themselves and may include strategies such as planning an escape route, packing an emergency bag, storing money, and making copies of important documents such as passports (Bader et al. 2019). Safety planning is crucial for women living in violent situations or attempting to leave during COVID-19. For those who were living with IPV prior to physical distancing, some strategies may need to be adapted or changed. Safety planning may require some redefinition as IPV professionals may be unable to meet with their clients in person. It is not always safe for a woman to reach out to a support worker, an informal supporter, or the police about her situation. Conducting risk assessments becomes increasingly difficult during a pandemic when contact with women seeking safety is reduced or limited to online or telephone conversations. Meaningful risk assessments may require in-depth conversations to adequately assess the risks a woman is facing.

Additionally, the risks a woman faces may become even more dynamic during a pandemic, and the assessment of risk should be completed regularly to monitor these potential changes. Professionals must think outside the box to address these situations and develop the increased safety measures necessary to cope or facilitate exit. Because some women and girls will not contact professionals, families, friends and communities must be educated on the warning signs for IPV and encouraged to find ways to reach out safely during the pandemic.

\section{Improving Access to Shelters and Safe Alternative Housing}

Having informal and formal support systems in place and knowing who to trust or go to in RRN communities is also key to accessing safe and supportive services such as shelters and alternate housing. As Bosch and Bergen (2006) argue an "extended network of family, friends, and the formal system must work together to be supportive to women in order to help women in abusive partner relationships become free from abuse" (p. 320). Shelter websites must also have up-to-date information to assist women in safety planning and to allow informal supporters to know how to make a referral (see Aujla 2010). Shelters should continue to raise awareness that they are open during the pandemic, and services are available for people needing to access them. Many shelters are taking in fewer families to abide by the social distancing restrictions and collaborating with local hotels to relocate women (Bogart 2020). IPV protocols around the collaborative work between shelters and hotels must be established. Some considerations include the need for aliases when women are registered in hotels so that their abusers cannot track them; outreach and supports from shelter workers to the hotels need to be put in place so that women can be safely supported while being housed in hotels; partnerships between hotels and shelters need to be developed so that all aspects of this novel form of housing are considered and well planned.

\section{Role of Technology and Safety}

In many areas, IPV service providers have switched to webbased communication and are only meeting clients where it is safe to do so. Access to information and help via the internet is much more limited in the RRN communities. As discussed above, problems can arise with poor internet service connections, and this can impact how victims receive online assistance and access resources. There is a pressing need for better internet infrastructure and commitment from all levels of government to help improve the resources in RRN communities.

Online safety planning apps are in development or available in some areas, and are helpful since abusers may limit telephone access or monitor the use of technology (see Bosch and Bergen 2006; van Gelder et al. 2020). The Staying Safer EVO safety planning app is specific to New Brunswick but may have information useful to women living in other areas of the country (see Jeffrey et al. 2019). The iCAN Plan 4 Safety app, ${ }^{7}$ is another online decisional aid that may be useful to women who are concerned for their safety while in isolation. We recommend expanded access and promotion of online decisional tools to help women assess risk and manage safety. Still, these tools will be useless if women are not provided with the resources to access them. Additionally, similar to van Gelder et al. (2020), we encourage IPV organizations to confirm that their websites can be accessed safely with quick exit features and easy steps to clear browsing data (see also Slakoff et al. 2020).

The Canadian government announced an email subscription program that will provide Canadians with email updates on COVID-19 in April 2020. Additionally, an online app provides mental health resources and a COVID-19 self-check and symptom tracker. ${ }^{8}$ Moving forward, we recommend that information about IPV be included in these resources, in order to increase the dissemination of information about warning signs and services available to victims and abusers. We believe this will be particularly useful to those living in RRN regions of the country.

\section{Future Research}

The U.N. Special Rapporteur on Violence Against Women, Dubravka Šimonović, has released a call for submissions on COVID-19 and the increase of IPV against women. We encourage Canadian researchers to respond to the U.N. call to

\footnotetext{
${ }^{7}$ The iCAN Plan 4 Safety app is funded by the Canadian Institutes of Health Research and can be accessed here: https://icanplan4safety.ca

${ }^{8}$ For more information on the online app from the Canadian government visit: https://ca.thrive/covid19app/home
} 
examine violence against women in quarantine or social distancing with an abuser and to provide relevant information in the RRN context of the COVID-19 pandemic that may inform risk assessment, risk management, and safety planning as we prepare for a possible second wave of this pandemic or future pandemics or crises. Investments must be made in knowledgegathering from informal supporters (e,g., family, friends, and neighbours), formal supporters (e.g., IPV shelter service providers and police officers) and women directly accessing services (e.g., shelters or outreach services). Such research will help determine what worked and what did not and whether adequate services were provided during the pandemic. Research should also be conducted with abusers and their service providers to learn what supports were available to men to cope with additional stress and to learn more about how corrections services monitored and supervised perpetrators of IPV during this time. It is through understanding the strengths and weaknesses of our responses to COVID-19, and post-disaster recovery, that we will learn how to better serve women at risk of IPV during future emergencies.

\section{Conclusion}

Women experiencing IPV in RRN communities now face the additional challenge of how to reconcile conflicting advice (directed to the public) about staying home and socially distancing themselves to prevent COVID-19 but also remaining safe from violence. We know that women in these communities are particularly vulnerable to violence at home, and the risks of violence increase where access to meaningful community supports are limited.

The recommendations made in this brief commentary are not meant to be exhaustive of all the steps necessary to support women facing IPV either during COVID-19 or afterwards. Instead, we have focused on a few specific concrete steps that can be taken quickly to enhance women's safety in RRN communities. We also know that there are competing demands on a limited pool of government resources during an emergency of this scope. However, we believe that nothing is more important than the safety of Canadian women, and we hope federal, provincial, territorial, and local governments will work together to rise to this challenge.

\section{References}

Abel, K. (1993). Drum songs: Glimpses of Dene history. Kingston: McGill-Queen's University Press.

Arriagada, P. (2016). First nations, Metis and Inuit women. Women in Canada: A Gender-based statistical report. Statistics Canada catalogue no. 89-503-X. Ottawa: Statistics Canada https://www150. statcan.gc.ca/n1/en/pub/89-503-x/2015001/article/14313 eng.pdf? st=togZc6hi.

Arriagada, P., Hahmann, T., \& O'Donnell, V. (2020). Perceptions of safety of indigenous people during the COVID-19 pandemic. StatCan COVID-19: Data to insights for a better Canada. Statistics Canada catalogue no. 4528001. Ottawa: Statistics Canada https://www150.statcan.gc.ca/n1/en/pub/45-28-0001/ 2020001/article/00071-eng.pdf.

Aujla, W. (2010). Domestic violence and immigrant women's access to services in Edmonton, Alberta. The Annual Review of Interdisciplinary Justice Research, 1, 58-76.

Bader, D., Doherty, D., Dumont-Smith, C., Guruge, S., Nepinak, J., Porteous, T., Campbell, M., Straatman, A. L., \& Dawson, M. (2019). Creating safety plans with vulnerable populations to reduce the risk of repeated violence and domestic homicide. Domestic Homicide Brief (6). London: Canadian Domestic Homicide Prevention Initiative ISBN: 978-1-988412-29-0.

Banman, V. L. (2015). Domestic homicide risk factors: Rural an durban considerations. The University of Western Ontario.; Beattie, S., \& Hutchins, H. (2015). Shelters for women in Canada, 2014. Ottawa, Canada: Statistics Canada.

Barrett, B. J., Fitzgerald, A., Peirone, A., Stevenson, R., \& Cheung, C. H. (2018). Help-seeking among abused women with pets: Evidence from a Canadian sample. Violence and Victims, 33(4), 604-626. https://doi.org/10.1891/0886-6708.VV-D-17-00072.

Barrett, B. J., Fitzgerald, A., Stevenson, R., \& Cheung, C. H. (2020). Animal maltreatment as a risk marker of more frequent and severe forms of intimate partner violence. Journal of Interpersonal Violence, 35(23-24), 5131-5156. https://doi.org/10.1177/ 0886260517719542 .

Beattie, S. \& Hutchins, H. (2015). Shelters for abused women in Canada, 2014. (catalogue no. 85-002-X). Statistics Canada.

Blondin, G. (1990). When the world was new: Stories from the Sahtu Dene. Yellowknife: Outcrop.

Bogart, N. (2020). Advocates scramble to help domestic abuse victims as calls skyrocket during COVID-19. CTV News. https://www. ctvnews.ca/health/coronavirus/advocates-scramble-to-helpdomestic-abuse victims-as-calls-skyrocket-during-covid-19-1. 4923109

Bollman, R. (2016). Rural demography update 2016. Rural Ontario Institute. http://www.ruralontarioinstitute.ca/file.aspx?id= 26acac18-6d6e-4fc5-8be6-c16d326305fe

Bosch, K., \& Bergen, M. B. (2006). The influence of supportive and nonsupportive persons in helping rural women in abusive partner relationships become free from abuse. Journal of Family Violence, 21(5), 311-320. https://doi.org/10.1007/s10896-006-9027-1.

Brockman, A. (2020). N.W.T. community leaders split on wisdom of keeping liquor stores open. CBC News. https://www.cbc.ca/news/ canada/north/nwt-liquor-stores-open-covid-19-1.5528874

Burczycka, M. (2019). Police-reported intimate partner violence in Canada, 2018. Ottawa, Canada: Canadian Cenre for Justice Statistics.

Campbell, M., Hilton, N. Z., Kropp, P. R., Dawson, M., Jaffe, P. (2016). Domestic violence risk assessment: Informing Safety Planning \& Risk Management. Domestic Homicide Brief (2). London: Canadian Domestic Homicide Prevention Initiative. ISBN 978-1988412-01-6. http://cdhpi.ca/sites/cdhpi.ca/files/Brief_2_Final_0. pdf

Canadian Centre on Substance Abuse and Addiction (2020). Canadians under 54 drinking more while at home due to COVID-19 pandemic. https://ccsa.ca/canadians-under-54-drinking-more-while-home-duecovid-19-pandemic

Canadian Femicide Observatory for Justice and Accountability (CFOJA) (2020). \#CallItFemicide 2019 Report Update. 
Canadian Radio-television and Telecommunications Commission (CRTC). (2019). Communications Monitoring Report, 2018. ISSN:2290-7866. https://crtc.gc.ca/pubs/cmr2018-en.pdf

Cava, M.A., Fay, K.E., Beanlands, H.J., McKay, E.A., \& Wagnar, R. (2005). The experience of quarantine for individuals affected by SARS in Toronto. Public health Nursing, 22(5), 398-406. https:// doi.org/10.1111/j.07371209.2005.220504.x.

CBC News. (2020a). Why watching alcohol intake is advised, but closing liquor stores would be a problem. www.cbc.ca/news/canada/london/ alcohol-covid-19-1.5509925

CBC News (2020b). Should the NWT government name the small community with a COVID-19 case? https://www.cbc.ca/news/canada/ north/naming-small-communities-covid-19-nwt-1.5523376

CBC News. (2020c). Province won't grant early release to domestic violence abusers. https://www.cbc.ca/news/canada/nova-scotia/n-swon-t-grant-early-release-to-abusers- 1.5527090

CBC News (2020d). YWCA director concerned after family violence shelter use drops to zero amidst pandemic. https://www.cbc.ca/ news/canada/north/domestic-violence-shelters-nwt-covid-19-1. 5556398

CDHPIVP. (2019). Trends and patterns in domestic homicides in Canada. 2010-2018. London: Canadian Domestic Homicide Prevention Initiative with Vulnerable Populations www.cdhpi.ca/ sites/cdhpi.ca/files/CDHPIVP GENERAL FINAL.pdf.

Faller, N. Y., Wuerch, M. A., Hampton, M. R., Barton, S., Fraehlich, C., Juschka, D., et al. (2018). A web of disheartenment with hope on the horizon: Intimate partner violence in rural and northern communities. Journal of Interpersonal Violence, 1-26. First published online July 18, 2018. https://doi.org/10.1177/0886260518789141.

Gearin, M., \& Knight, B. (2020) Family violence abusers using COVID19 as a form of abuse we have not seen before. ABC News. https:// www.abc.net.au/news/2020-03-29/coronavirus-family-violencesurge-in victoria/ 12098546

Godin, M. (2020). French government to house domestic abuse victims in hotels as cases rise during coronavirus lockdown. Time. https://time. com/5812990/france-domestic-violence-hotel-coronavirus/

Goodkind, J. R., Sullivan, C. M., \& Bybee, D. I. (2004). A contextual analysis of battered women's safety planning. Violence Against Women, 10(5), 514-533. https://doi.org/10.1177/ 1077801204264368.

Government of Canada. (2020). Coronavirus disease (COVID-19): Outbreak update. https://www.canada.ca/en/public-health/services/ diseases/2019-novel-coronavirus-infection.html

Government of Northwest Territories (NWT). (2020). News Release: Public Health Emergency Declared in the Northwest Territories. https://www.gov.nt.ca/en/newsroom/news-release-public-healthemergency-declared-northwest-territories

Helm, J. (2000). The people of Denedeh: Ethnohistory of the Indians of Canada's Northwest Territories. Kingston: McGill-Queen's University Press.

Jeffrey, N., Johnson, A., Richardson, C., Dawson, M., Campbell, M., Bader, D., Fairbairn, J., Straatman, A. L., Poon, J., \& Jaffe, P. (2019). Domestic violence and homicide in rural, remote, and northern communities: Understanding risk and keeping women safe. In Domestic homicide (7). London: Canadian Domestic Homicide Prevention Initiative ISBN 978-1-988412-34-4. http://cdhpi.ca/ sites/cdhpi.ca/files/Brief 7.pdf.

Le Page, I. (2020). Fears of domestic violence rise as millions confined over virus. CTV News. https://www.ctvnews.ca/health/coronavirus/ fears-of-domestic-violence-rise-as-millions-confined-over-virus-1. 4872437

Liao, C. (2020). COVID-19 has put a harsh spotlight on the anti-Asian racism that has always existed in Canada. CBC News. https://www. cbc.ca/news/canada/british-columbia/covid-19-has-put-a-harshspotlight-on-the-anti-asian-racism-that-has-always-existed-incanada-1.5572674
Lindhorst, T., Nurius, P., \& Macy, R. J. (2005). Contextualized assessment with battered women: Strategic safety planning to cope with multiple harms. Journal of Social Work Education, 41(2), 331-352. https://doi.org/10.5175/JSWE.2005.200200261.

Maki, K. (2018). Mapping VAW Shelters and Transition Houses: Initial Finding of a National Survey. Ottawa: Women's shelters Canada https://endvaw.ca/wpcontent/uploads/2018/10/mapping-VAWShelters-2018.pdf.

Maki, K. (2019). More Than a Bed: A National Profile of VAW Shelters and Transition Houses. Ottawa: Women's shelters Canada https:// endvaw.ca/wp content/uploads/2019/04/More-Than-a-Bed-FinalReport.pdf.

Michelin, L. (2020). Calls for help are way down - Raising concerns at the Red Deer women's shelter. Red Deer Advocate. https://www. reddeeradvocate.com/news/calls-for-help-are-way-down-raisingconcerns-at-the-red-deer-womens-shelter

Moffitt, P. (2004). Colonialization: A health determinant for pregnant Dogrib women. Journal of Transcultural Nursing, 15, 323-330. https://doi.org/10.1177/1043659604268959.

Moffitt, P., \& Fikowski, H. (2017). Northwest Territories research project for territorial stakeholders. Rural and Northern Community Response to Intimate Partner Violence. http://www2.uregina.ca/ipv/.

Moffitt, P., Fikowski, H., Mauricio, M., \& Mackenzie, A. (2013). Intimate partner violence in the Canadian territorial north: Perspectives from a literature review and a media watch. International Journal of Circumpolar Health, 72, 215-221. https://doi.org/10.3402/ijch.v72i0.21209.

Moreau, G. (2019). Canadian residential facilities for victims of abuse, 2017/2018. (statistics Canada catalogue no. 85-002-X). Statistics Canada. https://www150.statcan.gc.ca/n1/en/pub/85-002-x/ 2019001/article/00007-eng.pdf

National Collaborating Centre for Determinants of Health. (2020). Conversation series: health equity, determinants of health and COVID-19. http://nccdh.ca/workshops-events/entry/COVID-19webinar-conversation-series

National Collaborating Centre for Indigenous Health. (2019). Family violence as a determinant of First Nations, Inuit and Metis health. https://www.nccah-ccnsa.ca/docs/fact\%20sheets/social\% 20determinates/NCCAH fs familyviolence_EN.pdf

Native Women's Association of Canada (2020). Violence against Indigenous women during COVID-19 sparks calls for MMIWG plan. https://www.nwac.ca/violence-against-indigenous-womenduring-covid-19-sparks-calls-for-mmiwg-plan/

Northcott, M. (2011). Domestic violence in rural Canada. Victims of Crime Research Digest, 4(4), 9-14.

Office of the Chief Coroner for Ontario (2019). Domestic Violence Death Review Committee 2018 Annual Report. https:/www.mcscs.jus. gov.on.ca/english/Deathinvestigations/OfficeChiefCoroner/ Publicationsandreports/DVDRC2018Report.html

Peterman, A., Potts, A., O’Donnell, M., Thompson, K., Shah, N., OerteltPrigione S, van Gelder, N. (2020). Pandemics and violence against women and children. Washington, DC: Center for Global Development. Working paper: 528. https://www.cgdev.org/ publication/pandemics-and-violence-against-women-and-children

Roszell, T. (2020). COVID-19 adds new wrinkle to police response in New Brunswick. Global News. https://globalnews.ca/news/ 6743581/covid-19-police-response in-new-brunswick/

Roy, J., \& Marcellus, S. (2019). Homicide in Canada, 2018. (statistics Canada catalogue no. 85-002-X). Statistics Canada. https:// www150.statcan.gc.ca/n1/en/pub/85-002-x/2019001/article/00016eng.pdf

Royal Commission on Aboriginal Peoples. (1996). Report of the Royal Commission on Aboriginal Peoples. https://www.bac-lac.gc.ca/eng/ discover/aboriginal-heritage/royal-commission-aboriginal-peoples/ Pages/final-report.aspx 
Sandberg, L. (2013). Backward, dumb, and violent hillbillies? Rural geographies and intersectional studies on intimate partner violence. Affilia, 28(4), 350-365. https://doi.org/10.1177/ 0886109913504153 .

SaskTel (2020). Phones for a Fresh Start. https://www.sasktel.com/ about-us/Community/Phones+for+a+Fresh+Start

Sinha, M. (Ed.) (2013). Measuring violence against women: Statistical trends. Ottawa: Statistics Canada Canadian Centre for Justice Statistics. Catalogue no 85-002-X. https://www150.statcan.gc.ca/ n1/pub/85-002-x/2013001/article/11766-eng.pdf

Slakoff, D. C., Aujla, W., \& PenzeyMoog, E. (2020). The role of service providers, technology, and mass media when home isn't safe for intimate partner violence victims: Best practices and recommendations in the era of COVID-19 and beyond. Archives of Sexual Behavior, 49(6), 1-10. 10.1007\%2Fs10508-020-01820-w .

Smith, C. (2020). Women's shelters, sexual assault centres face funding shortfalls during COVID-19 pandemic. Global News. https:// globalnews.ca/news/6767984/womens-shelters-sexual-assaultcovid-19/

Stark, E. (2007). Coercive control: How men entrap women in personal life. New York: Oxford University Press.

Statistics Canada (2020). Canadian perspectives survey series 1: Impacts of COVID-19. The Daily. https://www150.statcan.gc.ca/n1/en/ daily-quotidien/200408/dq200408c-eng.pdf?st=w0doSCsg

The Star. (2020). Forced to stay home with their abusers, Canadian victims of domestic violence must 'choose between two pandemics'. https://www.thestar.com/news/canada/2020/04/20/forced-to-stayhome-with-their-abusers-canadian-victims-of-domestic-violencemust-choose-between-two-pandemics.html

Thomson, A., \& Chiu, E. (2020). N.S. shooting rampage highlights public threat of domestic violence: victim advocates. CBC News. https:// www.cbc.ca/news/canada/nova-scotia/shooting-rampage-publicthreat-domestic violence-1.5545726

Truth and Reconciliation Commission (2015). Survivors Speak. http:// nctr.ca/assets/reports/Final\%20Reports/Survivors_Speak_English_ Web.pdf

UNFPA (2020). Impact of the COVID-19 pandemic on family planning and ending gender-based violence, female genital mutilation and child marriage. Interim Technical Note. https://www.unfpa.org/ resources/impact-covid-19-pandemic-family-planning-and-endinggender-based-violence-female-genital

United Nations. (2020). UN chief calls for domestic violence 'ceasefire' amid 'horrifying global surge'. UN News. https://news.un.org/en/ story/2020/04/1061052

Usher, K., Bhuller, N., Durking, J., Gyamfi, N., \& Jackson, D. (2020). Family violence and COVID-19: Increased vulnerability and reduced options for support. International Journal of Mental Health Nursing. First published online April 20, 2020. https://doi.org/10. 1111/inm.12735.

Van Bortel, T., Basnayake, A., Wurie, F., Jambai, M., Karoma, A.S., Muana, A.T., Hann, K... Nellums, L.B. (2016). Psychosocial effects of an Ebola outbreak at individual, community and international levels. World Health Organization. https://www.who.int/bulletin/ volumes/94/3/15-158543.pdf

van Gelder, N., Peterman, A., Potts, A., O'Donnell, M., Thompson, K., Shah, N., \& Oertelt-Prigione, S. (2020). COVID-19: Reducing the risk of infection might increase the risk of intimate partner violence. EClinicalMedicine, 21, 100348. First published online April 11, 2020. https://doi.org/10.1016/j.eclinm.2020.100348.

Wendt, S., Chung, D., Elder, A., Hendrick, A., Hartwig, A. (2017). Seeking help for domestic and family violence: Exploring regional, rural, and remote women's coping experiences: Key findings and future directions. Australia's National Research Organisation for Women's Safety Limited. https://www.anrows.org.au/publication/ seeking-help-for-domestic-violence-exploring-rural-womenscoping-experiences-final-report/

Women and Gender Equality Canada (WAGE) (2020). Supporting women's shelters and sexual assault centres during COVID-19. https://cfc-swc.gc.ca/fun-fin/shelters-refuges-en.html

Women's Shelters Canada (WSC) (2020). Women's Shelters Canada Welcomes Opportunity to Distribute Federal Funds to VAW Shelters Across the Country. https://endvaw.ca/archives/news/ womens-shelters-canada-welcomes-opportunity-to-distributefederal-funds-to-vaw-shelters-across-the-country/.

World Health Organization (n.d.). Intimate partner violence and alcohol. https://www.who.int/violence_injury_prevention/violence/world_ report/factsheets/fs_intimate.pdf?ua=1

Wright, T. (2020). Violence against indigenous women during COVID19 sparks calls for MMIWG plan. CBC News. https:/www.cbc.ca/ news/canada/manitoba/violence-against-indigenous-womenaction\%09plan-covid-19-mmiwg-1.5563528

Wuerch, M. A., Giesbrecht, C. J., Price, J. A. B., Knutson, T., \& Wach, F. (2017). Examiningthe relationship between intimate partner violence and concern for animal care and safekeeping. Journal of Interpersonal Violence, 35(9-10), 1866-1887. https://doi.org/10. $1177 / 0886260517700618$.

Wuerch, M. A., Giesbrecht, C. J., Jeffery, N., Knutson, T., \& Wach, F. (2018). Intimate partner violence and concern for animal care and safekeeping: Experiences of service providers in Canada (brief report). Journal of Interpersonal Violence, Article first published online: August, 24, 2018. https://doi.org/10.1177/0886260518795503.

Wuerch, M. A., Zorn, K. G., Juschka, D., \& Hampton, M. R. (2019). Responding to intimate partner violence: Challenges faced among service providers in northern communities. Journal of Interpersonal Violence, 34(4), 691-711. https://doi.org/10.1177/ 0886260516645573 .

Publisher's Note Springer Nature remains neutral with regard to jurisdictional claims in published maps and institutional affiliations. 